\title{
A RARE CASE OF SPONTANEOUS PERFORATION OF CAECUM FOLLOWING SPINAL INJURY
}

Suresh Rathi ${ }^{1}$

\section{HOW TO CITE THIS ARTICLE:}

Suresh Rathi. "A Rare Case of Spontaneous Perforation of Caecum following Spinal Injury". Journal of Evolution of Medical and Dental Sciences 2014; Vol. 3, Issue 56, October 27; Page: 12839-12842,

DOI: $10.14260 /$ jemds/2014/3705

ABSTRACT: Perforation of healthy caecum is an uncommon condition. It may occur as result of distal large bowel obstruction, unrelieved volvulus of the caecum, trauma to right side of abdomen or ingested foreign bodies, e.g. a fish bone or tooth pick11.It may occur by endoscopy \& very rarely disease like typhoid, tuberculosis, chrohn's disease, amoebiasis \& malignancy. Spontaneous perforation of caecum in absence of any of above is exceedingly rare. We repot a case here following spinal injury with review of literature.

KEYWORDS: Tube Caecostomy, Peritonitis, Spontaneous perforation of caecum, Spinal injury.

INTRODUCTION: Spontaneous perforation of caecum is very rare condition. In an extensive research very few cases could be found. Low \& fairly described a case of perforation occurring in a patient suffering from tropical sprue. ${ }^{2}$ One case occurred following normal child birth ${ }^{3}$.Few cases reported after caesarean section.4,5 Two cases reported, where perforation occurred following left inguinal hernioraphy \& left nephrectomy respectively. ${ }^{1}$ Another case in an elderly woman had had a fall \& sustained injuries to left shoulder $\&$ chest wall. ${ }^{6}$

Another perforation due to adynamic ileus reported by Carlon Carsasdulla. ${ }^{7}$ Quenton Macmanus reported diastatic perforation of caecum without distal obstruction in 1977.8 Seltzer Dudley reported perforation of normal caecum 9 .Our case had injury to spine following heavy bag fall on her back. Perforation of anterior wall of caecum occurred four days after spinal injury.

CASE REPORT: A 60 year old female was admitted with history of injury to her back by fall of $50 \mathrm{~kg}$ sand bag from 10 feet height. She was c/o severe backache \& was unable to move. She was known hypertensive on telmesartan $20 \mathrm{mg}$ OD. She was of short stature and obese. On examination she was fully conscious with no neurological deficit. Pulse 98/mt, BP 100/70, afebrile. CVS \& respiratory system were normal. Abdomen was soft. No lump in abdomen. Bowel sounds present. There was severe tenderness on lower thoracic \& lumbar spine. She was unable to bear her wt \& walk.

INVESTIGATIONS: Hb10.2, WBC 8200 with polys 78\%, lymphocytes 20\%. Random blood sugar 89, creatinine $0.83 \&$ serum electrolytes were normal. Australia antigen+ive. X ray thoraco lumbar spine showed fracture L2 \&D6.MRI spine showed marrow edema D4, D6, D8 \& L2.Transverse fracture D6 \& L2. There was no spinal cord injury or compression. She was treated by orthopedic surgeon conservatively with analgesics \& bed rest. She had bowel opened once \& was passing flatus.

On $4^{\text {th }}$ day she felt discomfort in abdomen $\&$ was unable to pass motion. She was c/o pain in epigastrium \& distention of abdomen. An enema was given with poor result. She was referred to surgeon on $4^{\text {th }}$ day. On examination she was in agony, pulse $110 / \mathrm{mt}$ BP $110 / 70$, periphery was cold \& clammy Abdomen did not move on respiration. Board like rigidity. Liver dullness obliterated. 
Bowel sounds were absent. Per rectal examination empty rectum, no bleeding \& some fecal staining on gloves.
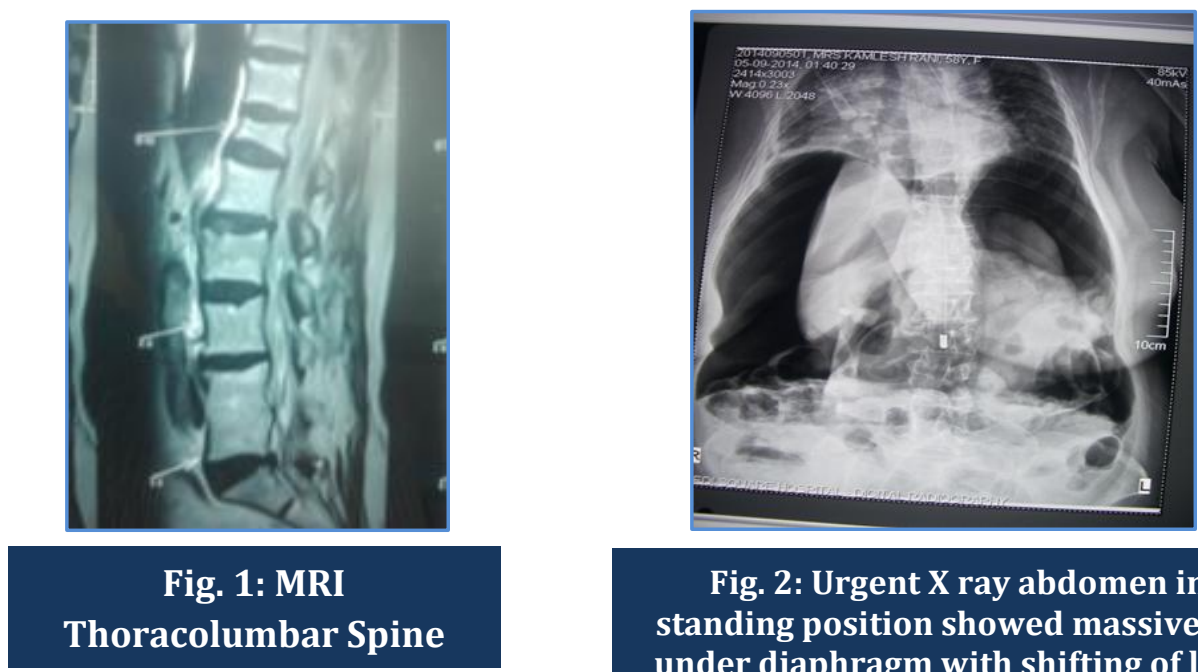

Fig. 2: Urgent $X$ ray abdomen in standing position showed massive gas under diaphragm with shifting of liver

Urgent $\mathrm{X}$ ray abdomen in standing position showed massive gas under diaphragm with shifting of liver medially (see pic.2) Her routine investigation again were normal. She was taken for emergency laparotomy.

OPERATION: CVP line was restored \& GA was given. Abdomen opened through midline incision. As soon as peritoneum was opened, free gas came out with fecal odor. There was no free fluid in peritoneal cavity. It looked clean. Stomach, duodenum \& small bowel were normal. There was a small perforation [pea size]. It was in anterior wall of caecum $7 \mathrm{~cm}$ from ileocaecal junction. Surrounding caecal wall was weak, stretched \& mildly inflamed. Rest of colon was normal. There was no growth \& stricture in distal colon causing obstruction.

There was no dilatation of small bowel \& colon..Peritoneal wash with normal saline was done. Tube caecostomy was performed using mallacot catheter with two wings of flower cut off. Tube Peritoneal drain was put in pelvic cavity. Abdomen was closed with loop nylon single layer. Pt was shifted to ICU. She made good post op recovery. Nasogastric tube was removed on $3^{\text {rd }}$ postoperative day.

Free fluids allowed on $4^{\mathrm{t}}$ day. Abdominal drain removed on $4^{\text {th }}$ day. She was on proper antibiotics, IV fluids, analgesics \& ppi. Semisolid diet stared on $5^{\text {th }}$ day postop. She was mobilized after two weeks due to spine injury. Gastrograffin enema was done. It reveled normal colon. No evidence of obstruction distally. Caecostomy tube was removed after this. There was some leakage for few days. It closed spontaneously thereafter. She is well after three week follow up at home. There is no discharge from tube site. She is taking normal meal with normal bowel movements.

DISCUSSION: Acute gastric dilatation \& small bowel ileus are known complications following abdominal operations and other procedures like reduction of a fracture femur and retroperitoneal operations, but colonic dilatation only rarely occurs. Present case is example of the latter, and this led to caecal perforation. 
In this case caecal perforation occurred after spine injury. The part played by ileocaecal valve in caecal perforation is uncertain. Some authors [Saeltzer \& Rhodes 9; Wangensteen ${ }^{10}$ believe that a competent ileocaecal valve is an important factor. It is interesting to note that in one of Yeo 'case 1 and ones of Robertson et al ${ }^{3}$ and Eckman et.al, 6 the terminal ileum as well as caecum was distended.

This does not mean that the ileocaecal valve was incompetent, but that the small bowel was unable to propel its contents into the grossly distended large bowel. Ischemic damage of caecal wall, as a result of distention, is main etiological factor for spontaneous perforation of caecum. The mortality of perforated caecum is high varying from $35 \%$ to $72 \%$ [Albert et al, ${ }^{11}$ Wangensteen, ${ }^{10}$

Lowman and Davis ${ }^{12}$. One important factor is delay in diagnosis, as clinical picture may not be correctly interpreted. Gross abdominal distention with slight pain and tenderness may be only positive finding. Bowel sounds are usually present, and there may be no vomiting or abdominal rigidity, Robertson et $\mathrm{al}^{3}$ and Yeo. ${ }^{1}$

In our case bowel sound was absent and there was gross distention of abdomen with board like rigidity. Abdomen X ray in standing position will reveal distended caecum with free gas under the diaphragm. Lowman \& Davis found that a caecum with a transverse diameter of $9 \mathrm{~cm}$ or over was indicative of impending perforation. ${ }^{12}$ The caecum usually remain distended even after perforation, ${ }^{13}$ probably because the tear becomes sealed off.

Measurement of the size of caecum is therefore helpful in anticipating and diagnosing caecal perforation. In our case there was massive tension pneumo peritoneum shifting liver medially \& all the bowels in lower abdomen. Caecum was not visible. Diagnosis was made only on laparotomy. The treatment of perforated caecum is by emergency laparotomy. At operation after exclusion of distal colonic lesion, a tube caecostomy is performed through the site of perforation if possible. Paul et. Al performed tube caecostomy by laproscopy. ${ }^{14}$

Ken Harris et al used endotracheal tube for caecostomy. ${ }^{15}$ Abdomen is closed with drainage. If no operative treatment is given, death usually ensues. Albers et al reported 14 deaths out of 15 when no operation was performed 11 , whereas in operated group the mortality was $30 \%$.In the postoperative period, barium enema studies are performed to exclude a colonic lesion that may have been missed at operation.

Caecostomy tube is usually removed after one week but we delayed it because patient had a spine fracture and was on bed rest \& not ambulatory for three weeks. She was not allowed to sit even. So high enemas \& laxatives were given. On removal of caecostomy tube, caecostomy wound should close spontaneously. In some cases formal operative closure might have to be done as in Yeo's case. ${ }^{1}$

SUMMARY: A case of spontaneous perforation of caecum following spinal injury is presented. Other cases are reviewed. Etiological factors, diagnosis and treatment of condition are discussed.

\section{REFERENCES:}

1. R Yeo. Spontaneous perforation of the caecum case reports and a review of the literature. Postgrad Med Journal [January 1967] 43, 65-67.

2. Low GC, Fairley NH. Fatal perforation of caecum in a case of sprue. Brit Med J ii, 678.

3. Robertson JA, Eddy WA, Vosseler A J. Spontaneous perforation of caecum without mechanical obstruction. Amer J Surg. 96, 448.

4. Hirsh MI. Spontaneous rupture of caecum, report of a case. Cent Afr J Med. 7, 49. 
5. H. Kaluend. Janseen. Spontaneous perforation of the caecum following caesarean section. Acta Obstetric \& Gynecologica, Scandinaviq Vol 51, Issue 4 \{Jan 1972], 381-383.

6. Eckman W G, Wenske F, Abramson W. Perforation of the caecum complicating adynamic ileus Amer J Surg. 96, 718.

7. Carlon Carsasdulla, Augustin Arbulu, Stefen Frommo, Charles Lucas. Caecal perforation due to adynamic ileus. Dis Col \& Rectum may June 1970 Vol 13 number 3.

8. Quentin Macmanus, Wiltnum W. Krippaehne. Diastatic perforation of caecum without distal obstruction. Arch Surg 1977112 [10] 1227-1230.

9. Seltzer Dudley, V. Rhodes George K. Diastatic perforation of normal caecum. Annals of surgery 101[5] 1257-1263. May 1935.

10. Wangansteen, O H. Intestinal Obstruction, $3^{\text {rd }}$ edn p39. Charles C Thomas, Springfield.

11. Albers J M, Smith LL, Carter R. Perforation of caecum. Ann Surg. 143, 251.

12. Lowman R M, Davis L. An evaluation of caecal size and impending perforation of caecum. Surg Gynec Obstet. 103. 711

13. Rack F J. Obstructive perforation of the caecum; Report of eight cases. Am J Surg. 84, 527.

14. Paul Vaughn, Richard T Schlinkert. Management of caecal perforation sec. to Ogiliviie' syndrome by Laparoscopic tube caecostomy. Journal of Laparoscopic Surgery Oct 19955 [5] 339-341.

15. Ken Harries. Ahmed A Shandall. Brian Stephenson. The Lancet Vol 350 Issue 9082 page 934 Sept 1997.

\section{AUTHORS:}

1. Suresh Rathi

\section{PARTICULARS OF CONTRIBUTORS:}

1. Consultant General Surgeon, Department of General Surgery, Medisquare Hospital, Indore.

\section{NAME ADDRESS EMAIL ID OF THE CORRESPONDING AUTHOR: \\ Dr. Suresh Rathi, \# 69, Anand Nagar, \\ Behind Inox, Indore, \\ Madhya Pradesh. \\ Email: sureshuro@rediffmail.com}

Date of Submission: 15/10/2014.

Date of Peer Review: 16/10/2014.

Date of Acceptance: 24/10/2014.

Date of Publishing: 27/10/2014. 